\title{
ECONOMIA CirCular APLICADA À DESMONTAGEM DE VEÍCUlOS EM FIM DE VIDA
}

Fernando Henrique Lermen (fernando.lermen@unespar.edu.br) - Universidade Estadual do Paraná, UNESPAR.

Vanessa Becker Bertoni (vanessabbertoni@gmail.com) - Universidade Federal do Rio Grande do Sul, UFRGS.

Vera Regina Piazza (vera.piazza@gmail.com) - Universidade Federal do Rio Grande do Sul, UFRGS. Rejane Maria Candiota Tubino (rejane.tubino@ufrgs.br) - Universidade Federal do Rio Grande do Sul, UFRGS.

Ângela de Moura Ferreira Danilevicz (angelamfd@ producao.ufrgs.br) - Universidade Federal do Rio Grande do Sul, UFRGS.

\section{RESUMO}

Sendo os veículos o meio de transporte preferido por mais de $55 \%$ da população mundial, quando o seu ciclo de vida se encerra, estes bens ficam inabilitados a exercer sua função, e são designados como Veículos em Fim de Vida. Existe no País uma demanda por peças de reposição de fácil acesso, onde os resíduos são destinados à reciclagem para a recuperação de materiais. O comissionamento prévio dos veículos em fim de vida para a reciclagem ocorre nos Centros de Remoção e Depósito. Este estudo propõe oportunidades de melhorias em Centros de Desmanche de Veículos e Centros de Remoção e Depósito. Os principais resultados obtidos demonstram que a Economia Circular está sendo implementada no Estado.

Palavras chave: Economia Circular; Veículo em Fim de Vida; Reutilização de peças; Reciclagem de resíduos automotivos; Sustentabilidade. 


\section{INTRODUÇÃO}

Os impactos de um crescimento urbano desordenado, aliado à existência de mais de 1,6 bilhões de pessoas vivendo abaixo da linha de pobreza, requerem uma atenção sistêmica em relação à produção de bens e serviços e ao consumo sustentável (HIGH-LEVEL POLITICAL FORUM ON SUSTAINABLE DEVELOPMENT, 2017). Para o Brasil, a projeção de crescimento é de 2,1\% em 2019 e de 2,5\%. no próximo ano. Segundo o Fundo Monetário Internacional, persiste no País um leve crescimento da demanda por bens e serviços atrelada às pressões para consolidação das finanças públicas, incluindo a reforma abrangente do sistema da previdência (UNITED NATION, 2019). Nesse sentido, governos e iniciativa privada enfrentam desafios para mitigar os impactos relativos ao consumo humano, cada um em sua alçada.

A aquisição de um veículo automotor está relacionada a preferências pessoais e influências externas, que determinam um comportamento, sustentável ou não, por parte dos consumidores. Estes hábitos resultam em uma significativa frota automobilística circulante em vias urbanas e estradas de todo o planeta. Segundo a Associação Nacional dos Fabricantes de Veículos Automotores - ANFAVEA, a produção brasileira de autoveículos vem mantendo ritmo ascendente, sendo que em 2018 foram licenciados 2,56 milhões de unidades, aumento de 14,6\% frente as 2,24 milhões de unidades vendidas em 2017. O setor automobilístico representa a maior cadeia produtiva do País com 10\% do PIB; o que se traduz em aproximadamente $22 \%$ do PIB de toda a cadeia da indústria de transformação; e 4\% de toda a indústria nacional (ANFAVEA, 2019).

E, quando um veículo não apresenta mais condições para a circulação, em consequência de acidente, de avaria, de mau estado ou por outro motivo, o ciclo de vida útil se encerra e o automóvel passa a ser caracterizado como um Veículo em Fim de Vida - VFV, constituindo um conjunto de resíduos (INSTITUTO DA MOBILIDADE E DOS TRANSPORTES, 2019). O Conselho Nacional de Trânsito - CONTRAN, através da Resolução 611 de 2016 (BRASIL, 2019), regulamentou a Lei 12.977 de 2014 (BRASIL, 2019), que regula e disciplina a atividade de desmontagem de veículos automotores terrestres. Através deste processo, as peças dos VFVs podem ser destinadas à reparação, reutilização ou convertidas em resíduos a serem reciclados, sendo que os rejeitos obtidos desses procedimentos devem ser dispostos adequadamente, como preconiza a Política Nacional de Resíduos Sólidos - PNRS (BRASIL, 2010). Assim, considerando a proporcionalidade entre o crescimento do número de veículos e a crescente população mundial, a demanda pela gestão de VFVs é premente. 
No Brasil, dentro da cadeia automobilística, são três os principais fornecedores de VFVs: o primeiro é composto pelo grupo de proprietários de veículos; o segundo congrega os Centros de Remoção e Depósito - CRDs, que recebem automóveis abandonados nas ruas, pátios, apreendidos, confiscados ou descartados indevidamente; e o terceiro é composto pelas Seguradoras, as quais detêm um plantel de veículos resultantes de acidentes e sinistros com perda total.

Quanto às seguradoras, desde 2016, o segmento tem fortalecido seu posicionamento como fornecedores de VFVs a partir da promulgação de legislação específica que promove a EC, a Resolução 336 (BRASIL, 2019) do Conselho Nacional de Seguros Privados. Essa resolução estabelece regras para a utilização de peças usadas oriundas de empresas de desmontagem, conforme lei específica, para a recuperação de veículos sinistrados com cobertura securitária. Complementando essa cadeia estão os Centros de Desmanches de Veículos - CDVs, os quais arrematam lotes de VFVs em leilões públicos (dos CRDs) ou diretamente das seguradoras. Os CDVs são credenciados junto aos Departamentos Estaduais de Trânsito - DETRANs e estão habilitados a realizar operações de desmontagem de VFVs para reaproveitamento de peças. Os materiais residuais dos processos de desmontagem são encaminhados à reciclagem. Sendo ss processos comerciais e operacionais dos CDVs o principal foco deste estudo, a questão de pesquisa que norteia o presente trabalho é: Qual é o potencial técnico, econômico e ambiental existente no mercado de VFVs no estado do Rio Grande do Sul? Os pressupostos relacionados são: que existe potencial para o crescimento do número de CDVs no estado do Rio Grande do Sul; e que existe diferença significativa na aquisição de peças de veículos oriundos de CRDs e os de seguradoras.

\section{REVISÃO TEÓRICA}

\subsection{Economia Circular}

Uma série de fatores indicam que o modelo linear é constantemente desafiado pelo próprio contexto em que opera, sendo necessária uma mudança mais consistente no sistema operacional da economia tradicional (ELLEN MACARTHUR FOUNDATION, 2015). Dentre estes fatores, estão as perdas econômicas e de resíduos. Uma das ameaças mais expressivas é a degradação dos sistemas naturais, que apresenta consequências ambientais negativas relacionadas ao modelo linear, comprometendo cada dia mais a produtividade das economias e os sistemas de provimento à vida no Planeta (POTTING et al., 2017). 
Com o propósito de reduzir o consumo de recursos e materiais naturais e minimizar a produção de resíduos, existem várias estratégias a serem implementadas em uma cadeia de suprimentos, de modo a estabelecer uma EC. Estas estratégias, organizadas por ordem de prioridades, de acordo com seus níveis de circularidade, estão demonstradas na Figura 1.

Considerando a rota dos dez Rs, do Ro estabelecido como Recusar, até o R9 - Recuperar, passando sucessivamente pelo Repensar (R1), Reduzir (R2), Reutilizar (R3), Reparar (R4), Restaurar (R5), Remanufaturar (R6), Resignificar (R7) e Reciclar (R8), a inovação em tecnologias é uma condição permanente para estabelecer a EC, partindo-se de uma EL. As transições para a EC, geralmente prescindem de inovação e de mudanças socioinstitucionais. A inovação pode estar ligada à tecnologia, ao design de produto e aos meios de receita financeira atrelada aos negócios. A mudança socioinstitucional envolve a revisão de regras, costumes e crenças.

Figura 1 - Estratégias da circularidade na cadeia de suprimentos. Fonte: Potting et al. (2017)

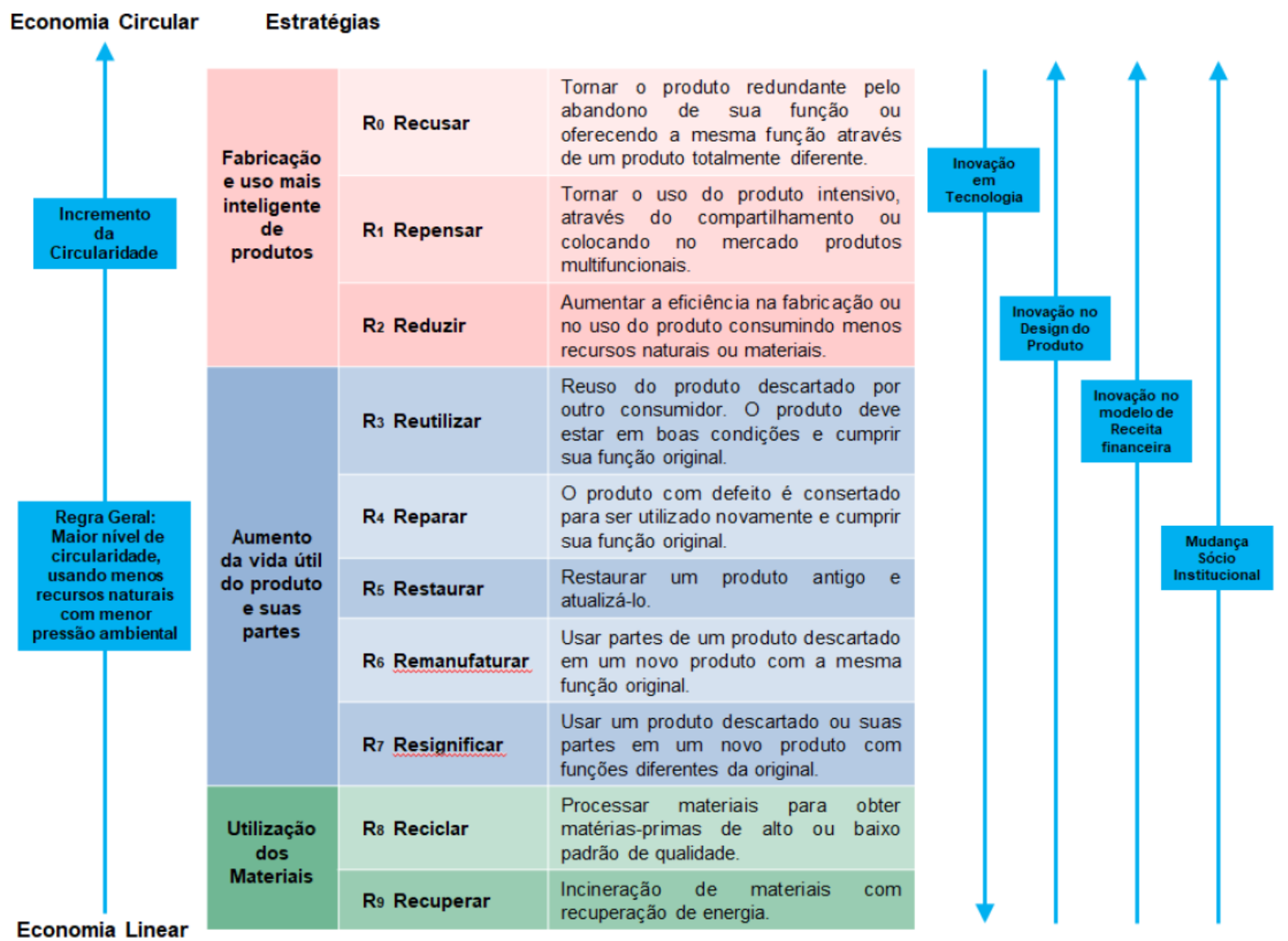

Na Figura 1, observam-se três tipos de transições para a EC, distintas entre si através do uso da tecnologia nas cadeias de produtos: O primeiro tipo de transição para a EC fundamentada 
em uma tecnologia radicalmente nova e específica. Também é necessária uma mudança socioinstitucional para que a nova tecnologia tenha seu lugar na sociedade. Um exemplo típico é o recente surgimento do bioplástico que já garantiu sua posição de vanguarda. No segundo tipo de transição, é a mudança socioinstitucional e a inovação tecnológica desempenhando um papel secundário. Configura o terceiro tipo de transição para a EC, aquela em que a mudança socioinstitucional é o centro, mas tem seu desempenho facilitado por uma tecnologia habilitadora. Nesta transição, um agente é detentor de um determinado produto e com ele presta serviços, promovendo mudanças socioinstitucionais. É preciso utilizar também a tecnologia da informação, como meio para vincular os provedores de serviços e seus potenciais usuários.

Um maior nível de circularidade de materiais em uma cadeia de produtos significa que as matérias permanecem na cadeia por mais tempo, e podem ser aplicadas novamente após a adequada destinação dos resíduos, preferencialmente mantendo a qualidade original. Como resultado, em princípio, são necessários menos recursos naturais para produzir novos materiais, necessários à fabricação de produtos.

A EC está baseada em três princípios. O primeiro, trata da preservação e do aumento do capital A otimização e o rendimento dos recursos pela circulação de produtos, componentes e materiais estão inseridos no segundo princípio. O terceiro princípio aborda a promoção da eficácia do sistema, revelando e criando externalidades negativas (ELLEN MACARTHUR FOUNDATION, 2015).

\subsection{Veículos em fim de vida}

No Brasil, os licenciamentos de veículos novos em 2018 foram de 2,1 milhões de unidades, configurando um aumento de 11,6\% frente aos 1,9 milhões de unidades registradas em 2017 (ANFAVEA, 2019). No final do ano de 2017, a frota circulante era de aproximadamente 43,4 milhões de autoveículos no País. A fração correspondente aos Automóveis foi de 36,0 milhões de unidades. A relação entre a população residente e a frota de autoveículos se manteve em 4,8 habitantes por veículo; e a idade da frota foi de nove anos e sete meses neste mesmo ano (SINDIPEÇAS, 2018).

À medida que a frota torna-se inapropriada à circulação, mediante avarias, sinistros, falhas mecânicas, ou por impedimento judicial, os veículos terminam seu ciclo de vida útil e tornamse VFVs (COIMBRA, 2017). Veículos são bens móveis que pode ter incorporado em sua estrutura três mil a 30 mil peças, dependendo do modelo, tamanho e forma de fabricação. As 
peças estão alocadas em diferentes setores da estrutura. Cada setor possui funcionalidades específicas desempenhadas por diferentes Sistemas, sendo estes: Elétrico; Arrefecimento; Freio; Rodagem; Injeção; Ignição; e Transmissão (VALORCAR, 2015).

A composição de um VFV depende dos materiais utilizados em sua fabricação. As estruturas e os materiais são determinantes para o correto manejo na desmontagem para o reuso de peças e o reaproveitamento dos resíduos (CUELLAR, 2009).

A literatura apresenta variações das quantidades de materiais empregados em veículos leves, porém o aço, cuja constituição é de $98,5 \%$ de ferro, é responsável por 50 a $70 \%$ do peso de um VFV. O plástico é o segundo material e sua quantidade pode variar entre 8 a $15 \%$.

Além dos componentes sólidos, os VFVs possuem uma série de fluidos de limpeza, desobstrução, refrigeração e lubrificação que somados, totalizam aproximadamente 25 litros, excluindo o combustível do VFV (XIA et al., 2016). A especificação destes líquidos está apresentada na Tabela 1.

TABELA 1 - Especificação dos fluidos de um VFV. Fonte: Xia et al. (2016)

\begin{tabular}{lcc}
\hline \multicolumn{1}{c}{ Fluidos } & Volume $(\mathrm{ml})$ & $\%$ \\
\hline Líquido de refrigeração & 6.100 & 24,80 \\
Líquido de lavagem do para-brisa & 1.850 & 7,52 \\
Fluido de freio & 330 & 1,34 \\
Fluido da transmissão da embreagem & 160 & 0,65 \\
Óleo hidráulico do mecanismo de direção & 740 & 3,01 \\
Óleo de motor & 4.210 & 17,11 \\
Fluido de transmissão automática & 6.520 & 26,50 \\
Óleo da engrenagem transmissão manual & 2.540 & 10,33 \\
Amortecedor de óleo hidráulico & 1.010 & 4,11 \\
Óleo de engrenagem diferencial & 1.140 & 4,63 \\
\hline TOTAL & $\mathbf{2 4 . 6 0 0}$ & $\mathbf{1 0 0}$ \\
\hline
\end{tabular}

Além do fluido de transmissão, o líquido de refrigeração e o óleo lubrificante do motor representam juntos, mais de $50 \%$ dos fluidos presentes em um VFV.

\subsection{ECONOMIA CIRCULAR APLICADA AOS VFVS}

Gerrard \& Kanlinkar (2007) abordam a questão do aumento da recuperação de peças VFVs e da redução do uso de substâncias perigosas na fabricação de veículos.

A indústria automotiva vem investindo no Design for Disassembly - DfD para o reuso e remanufatura de peças, uma vez que estes são preferíveis à reciclagem. Além disso, estudos 
comprovam que reciclagem tradicional economiza dez vezes mais energia do que a recuperação de energética aplicada ao mesmo resíduo. Engenheiros têm sido encorajados a projetar para a desmontagem, evitando o uso de agentes adesivos e juntas soldadas, e, sempre que possível, usando grampos ou parafusos facilmente removíveis (GERRARD; KANDLIKAR, 2007).

Futuramente, o processo de desmontagem deve considerar um índice de recuperação que deve auxiliar as montadoras na implementação de estratégias de recuperação, considerando a eficiência do projeto de desmontagem, as estimativas do tempo total de desmontagem direta e indireta, a sequência ótima de desmontagem e o custo da desmontagem (GO et al., 2011).

A Tabela 2 é um produto do estudo, cujos dados estão especificados a seguir. A meta é banir a disposição final de rejeitos contaminados em aterros.

TABELA 2 - Reciclagem de VFVs em novos produtos. Fonte: Vermeulen et al. (2011)

\begin{tabular}{|c|c|c|}
\hline Partes do VFV & Material & Reciclado como \\
\hline Janelas & Vidro & Azulejos \\
\hline Assentos & Espuma de vidro & Materiais de isolamento acústico para veículos \\
\hline Corpo, tronco, capô e portas & Aço & Partes de veículos e produtos de ação em geral \\
\hline Fios de cobre & Cobre & $\begin{array}{l}\text { Produtos de cobree motores (reforço de alumínio } \\
\text { fundido) }\end{array}$ \\
\hline Parachoques & Resina & $\begin{array}{l}\text { Parachoque, peças de interiors, caixa de } \\
\text { ferramentas e outros objetos }\end{array}$ \\
\hline Radiadores & Cobre e alumínio & $\begin{array}{l}\text { Lingotes para armas de fogo e produtos de } \\
\text { alumínio }\end{array}$ \\
\hline $\begin{array}{l}\text { Oléo de refrigeração do motor e } \\
\text { engranagens }\end{array}$ & Óleo & $\begin{array}{l}\text { Refinamento ou Combustível alternativo para } \\
\text { caldeiras e incineradores }\end{array}$ \\
\hline $\begin{array}{l}\text { Motor de transmissão, supensão e } \\
\text { rodas }\end{array}$ & Aço e alumínio & Produtos de aço e alumínio \\
\hline Catalizador (conversor catalítico) & Metais preciosos & $\begin{array}{l}\text { Recicladores catalíticos ou reciclagem de metais } \\
\text { preciosos }(\mathrm{Pt}, \mathrm{Pd}, \mathrm{Rh}, \mathrm{Ir})\end{array}$ \\
\hline Pneus & Borracha & $\begin{array}{l}\text { Recuperação de matérias-primas e energia } \\
\text { (Blendagem e Coprocessamento) }\end{array}$ \\
\hline
\end{tabular}

A obtenção de materiais reciclados originários de VFVs tem sido amplamente estudada em função dos impactos projetados nos ambientes em que se encontram. Estes impactos são resultado do design e da heterogeneidade de materiais utilizados na fabricação dos automóveis. Outra interferência é a ampla faixa de idades das frotas de VFVs nos mais distintos países. 
Consequentemente, é difícil prever a quantidade e a diversidade de matérias presentes, mas equalizando-se dados pode-se estimar a presença de grupos de materiais em um VFV (SOO et al., 2017).

A desmontagem dos VFVs no Brasil foi homologada pela Lei Federal 12.977 de 2014, a qual regula e disciplina a atividade de desmontagem de veículos automotores terrestres (BRASIL, 2019). O Artigo $3^{\text {o }}$ desta Lei define que "a atividade de desmontagem somente poderá ser realizada por empresa de desmontagem registrada perante o órgão executivo de trânsito do Estado ou do Distrito Federal em que atuar". No âmbito estadual, a Lei 12.745 de 2007, em seu Artigo $5^{\circ}$. estabelece a exclusividade para adquirir "sucata e materiais inservíveis oriundos de veículos automotores às entidades regularmente credenciadas como Centro de Desmanche de Veículos CDV pelo DETRAN/RS". Assim, somente um CDV credenciado tem permissão para a comercialização de partes, peças e acessórios automotivos oriundos de veículo sinistrado ou qualquer outro veículo automotor adquirido com o fim de desmontagem (RS, 2007).

\section{METODOLOGIA}

Essa pesquisa adotou as Design Research Methodology - DRM, proposto por Blessing e Chakrabarti (2009). O DRM é uma metodologia que estimula a criação e a avaliação empírica de um modelo ou teoria da situação desejada, o que aumenta a probabilidade de se produzir resultados que possam ser utilizados na prática. Adicionalmente, o DRM enfatiza a natureza iterativa do processo de pesquisa que possibilita a flexibilidade da aplicação dos métodos de trabalho que apoiam o planejamento e implementação das pesquisas (BLESSING; CHAKRABARTI, 2009). Os autores ainda relatam que a metodologia consiste em quatro estágios, sendo eles: i) Elucidação da Pesquisa; ii) Estudo Descritivo I; iii) Estudo Prescritivo; iv) Estudo Descritivo II. O framework base do método DRM apresenta-se na Figura 2, podendo ser realizado de maneira simultânea e não-linear.

Figura 2 - DRM Framework: Meios básicos, estágios e principais resultados 


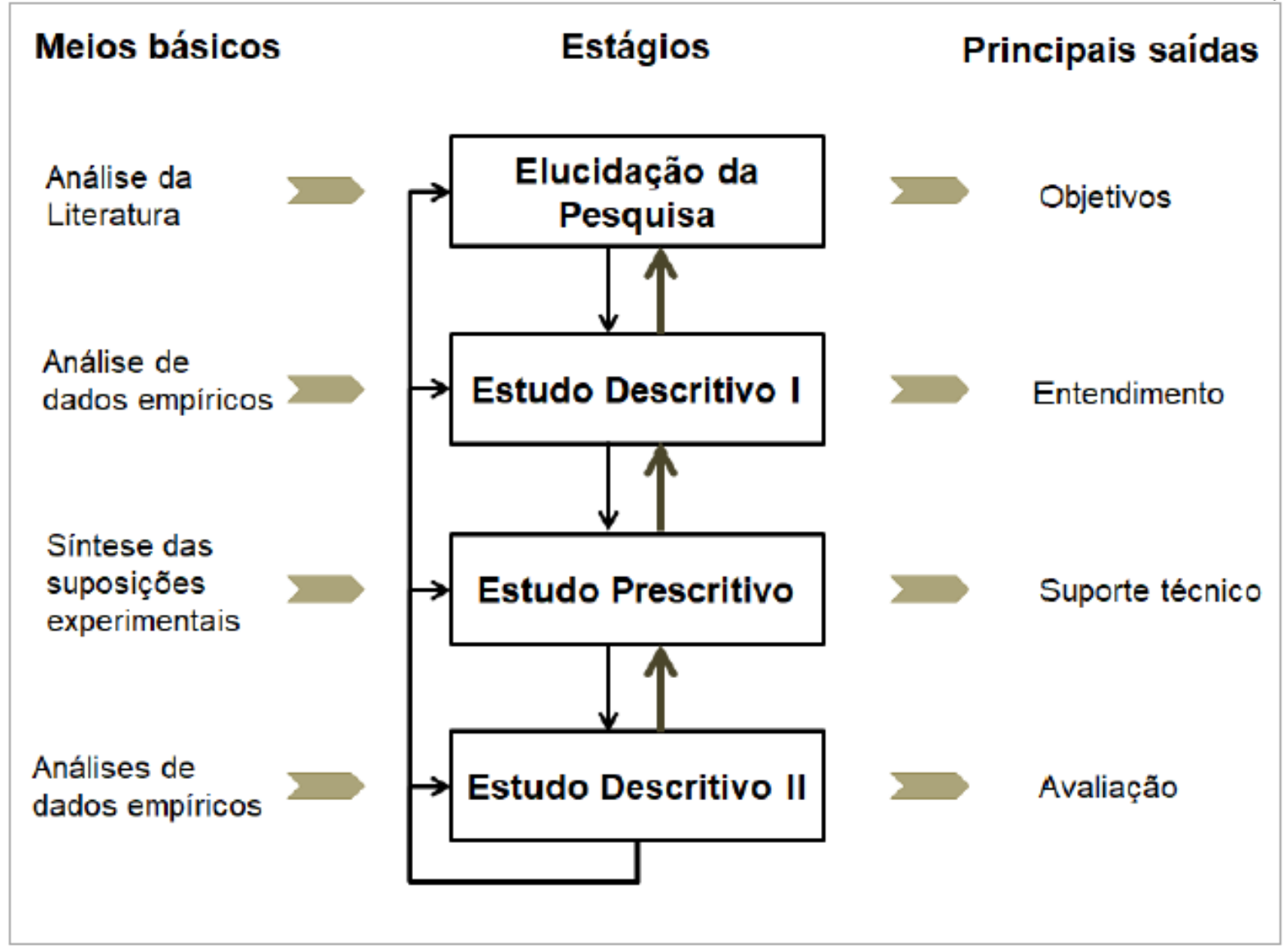

DRM é um método que visa agregar conhecimento na criação de novos modelos, processos, planos ou procedimentos, que tenham um fim específico e uma aplicação prática na resolução de problemas gerenciais (PIERONI, 2021). Apoiando-se nas etapas supracitadas e para cumprir o objetivo geral da pesquisa, cinco capítulos (Introdução, Referencial Teórico, Procedimentos Metodológicos, Resultados e Discussões e Conclusão) foram ordenados para adequar-se aos quatro estágios do DRM (Tabela 3).

Tabela 3- Estágios do DRR

\begin{tabular}{|c|c|c|c|}
\hline Estágio do DRM & $\begin{array}{l}\text { Capítulo da } \\
\text { Dissertação }\end{array}$ & Meios básicos & Resultados para a Dissertação \\
\hline $\begin{array}{l}\text { Estágio } 1 \text { - Elucidação } \\
\text { da Pesquisa }\end{array}$ & 1 - Introdução & Definir objetivos e método da pesquisa. & Validação dos objetivos. \\
\hline \multirow[b]{2}{*}{$\begin{array}{l}\text { Estágio } 2 \text { - Estudo } \\
\text { Descritivo I }\end{array}$} & \multirow[b]{2}{*}{2 - Referencial Teórico } & $\begin{array}{l}\text { Identificação de bases referenciais da EC ligada à } \\
\text { desmontagem veicular; e }\end{array}$ & \multirow{2}{*}{$\begin{array}{l}\text { Snowball para identificar melhorias } \\
\text { contínuas na desmontagem para } \\
\text { obter qualidade e agregar valor } \\
\text { comercial às peças e resíduos. }\end{array}$} \\
\hline & & $\begin{array}{l}\text { Estabelecer métricas para detectar indicadores e o } \\
\text { fluxo de valor dos resíduos gerados a partir dos } \\
\text { VFVs. }\end{array}$ & \\
\hline \multirow[t]{2}{*}{$\begin{array}{l}\text { Estágio } 3 \text { - Estudo } \\
\quad \text { Prescritivo }\end{array}$} & \multirow[t]{2}{*}{$\begin{array}{l}3 \text { - Procedimentos } \\
\text { Metodológicos }\end{array}$} & $\begin{array}{l}\text { Desenvolver modelo conceitual da geração de } \\
\text { resíduos a partir de VFVs; e }\end{array}$ & $\begin{array}{l}\text { Práticas e ferramentas de } \\
\text { desmontagem; e } \\
\text { Criar questionário qualitativo a ser } \\
\text { aplicado nos CDVs. }\end{array}$ \\
\hline & & Criar questionário qualitativo a ser aplicado nos & Validação do atual modelo de EC \\
\hline
\end{tabular}


CDVs. nos CDVs.

4 - Resultados e Criação do Macrofluxo com mapeamento dos Discussões

Estágio 4 - Estudo

Descritivo II
Avaliação dos CDVs e CRDs sob a perspectiva da inovação e das possibilidades de crescimento para a consolidação de uma EC para VFVs.
5 - Considerações Finais
Confirmar hipóteses e objetivos da pesquisa.
Contribuições e limitações da pesquisa; e sugestões de trabalhos futuros.

\section{RESULTADOS E DISCUSSÃO}

Para o embasamento teórico desta pesquisa, foi desenvolvido um Macrofluxo de forma a ampliar a visão sistêmica sobre a desmontagem de VFVs e a destinação dos resíduos gerados nos processos de desmantelamento. Este diagrama aclara como a EC tem efeito a partir da constituição de um VFV, passando pela sua desmontagem e/ou compactação, pelo reuso de peças, até a destinação adequada dos materiais secundários aptos à reciclagem.

Estas operações fazem parte do gerenciamento de resíduos da cadeia automotiva, partindo do ponto em que o veículo se converte em VFV no estado do Rio Grande do Sul. O diagrama não contempla a gestão de resíduos produzidos nas montadoras de automóveis, nos sistemistas, nas concessionárias, nas oficinas mecânicas e nos desmanches clandestinos. 


\subsection{CENTROS DE DESMANCHE DE VEÍCULOS}

Os Centros de Desmanche de Veículos - CDVs, dentro de sua atribuição específica regulamentada pela Lei Federal no 12.977 de 2014 que autoriza a desmontagem de veículos automotores terrestres, se constituem em um negócio organizado para desmantelar VFVs adquiridos em leilões. O objetivo é a retirada de peças e partes automotivas que irão ser reinseridas no mercado através de operações comerciais de venda. A demanda de mercado é, em si mesma, o propósito deste tipo de negócio, que promove uma reinserção de peças, recondicionadas ou não, através da venda em estabelecimento comercial instalado no próprio CDV; ou ainda, através de venda via internet e outras plataformas.

\subsection{CENTROS DE REMOÇÃO E DEPÓSITO}

Os Centros de Remoção e Depósito CRDs são empresas privadas credenciadas pelo DETRAN/RS para gerenciar a remoção e guarda dos veículos automotores recolhidos pelas autoridades competentes do Estado. As situações em que o veículo é removido para um CRD podem ser: uma infração de trânsito; o envolvimento em acidente de trânsito com lesões corporais; a retenção do veículo para investigações; e/ou quando o automóvel é fruto de furto ou roubo, ficando devidamente guardado até a autorização da sua devolução pela autoridade policial ou juiz criminal.

Os CRDs são um repositório de veículos sucateados ou que não estão aptos á circulação (material inservível como é denominado no DETRAN/RS). Periodicamente os CRDs editam leilões de sucatas, onde lotes de VFVs são adquiridos, e posteriormente, se convertem em matérias primas secundárias através da reciclagem. Este ciclo que se fecha, substituindo principalmente a mineração de materiais ferrosos, além de reduzir a contaminação de solos e evitar a propagação de doenças transmitidas por vetores.

\subsection{PROPOSIÇÃO DE MELHORIAS NOS CDVs e CRDs}

Nos CRDs, sinalizado no Macrofluxo da Figura 3 na rota de cor rosa, as proposições de melhorias são objeto de estudo dos técnicos do DETRAN/RS, encarregados de melhorar processos internos e externos de forma a desobstruir os pátios e melhorar a qualidade das sucatas produzidas. Neste estudo foi possível identificar que a gestão para os leilões requer maior atenção por parte da autarquia de forma a desafogar os depósitos e impedir a deterioração dos VFVs expostos à intempérie. 
O Macrofluxo foi construído para o melhor entendimento da constituição de um VFV a partir de um veículo. A partir daí, pode-se identificar as rotas para o reuso de peças e a reciclagem de materiais secundários. Ao mesmo tempo a EC recomenda melhorar os fluxos de resíduos, qualificando-os e evitando a disposição final destes. Por este motivo, sugere-se uma flexibilidade aplicada aos fluxos na área da Gestão dos Resíduos. Nesta parte do esquema, foram inseridas novas etapas como forma de extrair uma maior valoração (\$) dos materiais 
Figura 3 - Macrofluxo do processo de desmontagem de VFVs e destinação de Resíduos

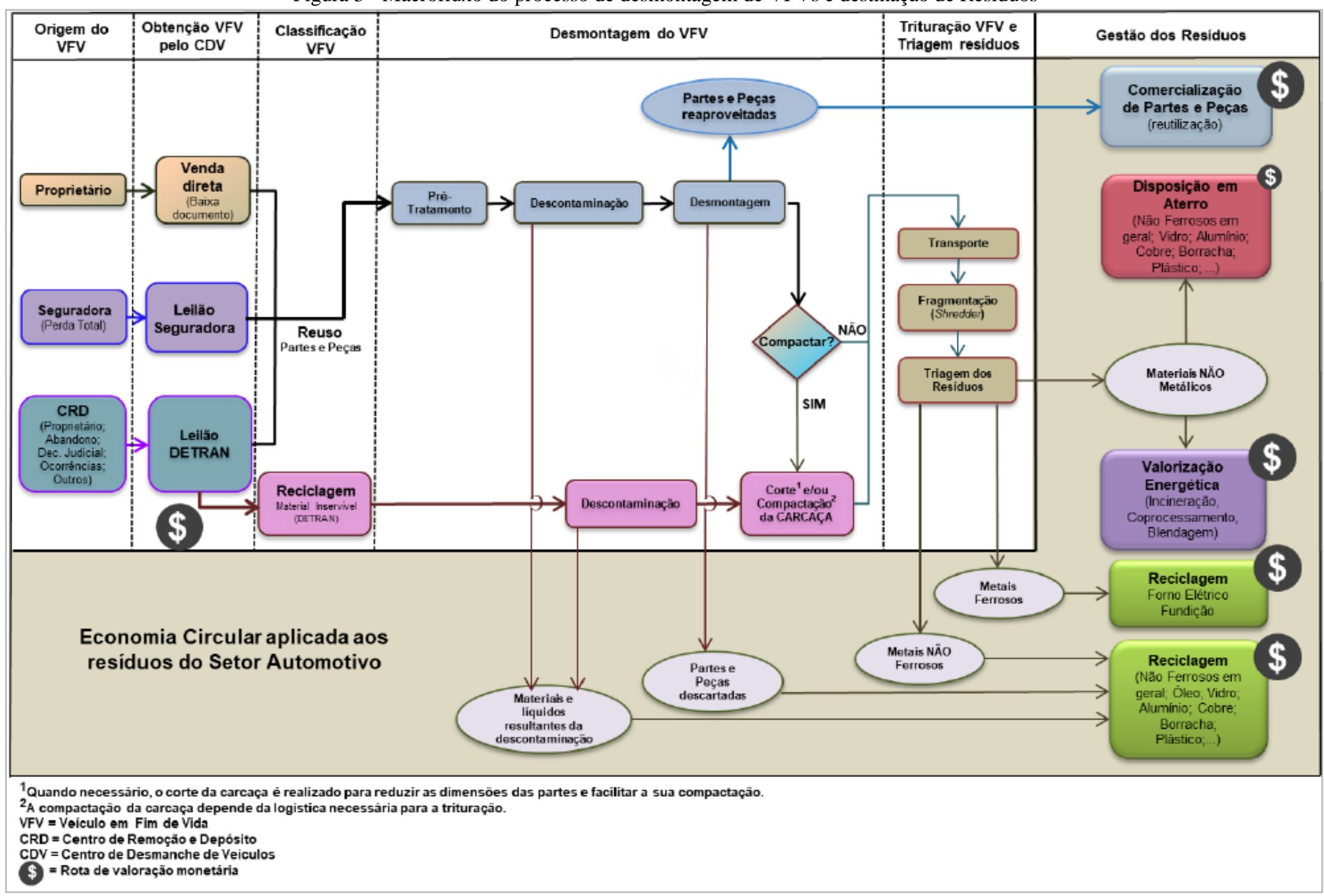


residuais e a máxima condição energética possível, eliminando linearidades e promovendo circularidades.

A medida que novas tecnologias se tornam disponíveis, o reaproveitamento energético aumenta e minimiza a extração de recursos naturais para a produção de bens de consumo. No esquema proposto, aparece o processo de incineração, especialmente recomendado para processar os rejeitos já depositados em aterros. Assim, este fluxo sugere possibilidades para que a EC aplicada aos VFVs no estado do Rio Grande do Sul, siga sendo ampliada pela resignificação dos resíduos. São sugeridas rotas alternativas para o gerenciamento integrado dos materiais, com utilização de outras técnicas de tratamento e reciclagem.

\section{Conclusões}

Os VFVs são veículos, muitos deles destituídos de sua função original, e outros em perfeito estado ou com pequenas avarias, como os automóveis provenientes de seguradoras. Os resíduos destes automóveis são de responsabilidade compartilhada entre montadoras e proprietários (BRASIL, 2010b). O objetivo desta Dissertação foi o de propor oportunidades de melhorias em CDVs e CRDs de forma a maximizar o aproveitamento dos resíduos para ampliar e aperfeiçoar a EC relacionada aos VFVs no Estado do Rio Grande do Sul.

Neste contexto, foram apresentadas cinco proposições relacionadas aos CDVs, quais sejam: (i) ampliação do padrão de qualidade das peças retiradas; (ii) melhor segregação dos resíduos gerados; (iii) fomento à homologação dos desmanches junto ao DETRAN/RS; (iv) fortalecimento do Sindicato do CDVs do Estado; e (v) unicidade nas reinvindicações junto ao DETRAN/RS.

Em relação aos CRDs, foram sugeridas duas proposições de forma a diminuir a informalidade: (i) tornar dinâmica a gestão de leilões de VFVs; (ii) flexibilizar as rotas da gestão de resíduos para eliminar rejeitos e ampliar a quantidade e a qualidade de recicláveis, especialmente os materiais não ferrosos.

Considerando-se a totalidade destas contribuições, é possível concluir que, apesar de ocorrerem de forma isolada, as propostas para combater a informalidade e o mercado ilegal estão inseridas na cadeia automotiva e existe sinergia entre as mesmas. Isso faz com que, muitas destas proposições possam ser determinantes para a implantação de melhoria contínua nos CDVs existentes, ao mesmo tempo em que estejam sendo implementadas nos desmanches ainda não homologados pelo DETRAN/RS. 


\section{REFERÊNCIAS}

$\begin{array}{lll}\text { "ANFAVEA. } & \text { Estatísticas, } & \text { Disponível }\end{array}$ em:<http://www.anfavea.com.br/docs/SeriesTemporais_Autoveiculos.xlsm r/estatisticas.html >. Acesso em 10 jan. 2021"

Blessing, L. T., \& Chakrabarti, A. (2009). DRM: A design reseach methodology (pp. 13-42). Springer London.

BRASIL, M. do M. A. Lei n. 12.305, de 2 de agosto de 2010. Política Nacional de Resíduos Sólidos. Lei no 12.305, de 2 de agosto de 2010, que institui a Política Nacional de Resíduos Sólidos; altera a Lei no 9.605, de 12 de fevereiro de 1998; e dá outras providências; e legislação correlata. 2010. p. 77

BRASIL. Medida Provisória no 843 de 5 de julho de 2018. DOU 6 jul. 2018. Disponível em: < http://www.planalto.gov.br/ccivil_03/_ato2015-2018/2018/Mpv/mpv843.htm > Acesso em 12 jan. 2019.

Coimbra, N. D. S. (2017). Sistema de reciclagem de veículos em final de vida: uma proposta ambientalmente mais sustentável para o cenário brasileiro.

Cuellar, R. (2009). Estudio de análisis, evaluación y definición de estrategias de solución de la corriente de residuos generada por los vehículos usados al final de su vida útil. México: semArnAt-IPN. Recuperado de http://biblioteca. semarnat. gob. mx/janium/Documentos/Ciga/Libros2011/CD000930. pdf.

ELLEN MACARTHUR FOUNDATION. Towards the Circular Economy

GERRARD, J.; KANDLIKAR, M. Is European end-of-life vehicle legislation living up to expectations? Assessing the impact of the ELV Directive on "green" innovation and vehicle recovery. Journal of Cleaner Production, v. 15, n. 1, p. 17-27, 2007.

GO, T. F.; WAHAB, D. A.; RAHMAN, M. N. A.; RAMLI, R.; AZHARI, C. H. Disassemblability of end-of-life vehicle: A critical review of evaluation methods. Journal of Cleaner Production, v. 19, n. 13, p. 1536-1546, 2011.

INSTITUTO DA MOBILIDADE E DOS TRANSPORTES. Veículos em Fim de Vida - VFV. Disponível em: $<$ http://www.imtip.pt/sites/imtt/Portugues/Veiculos/CancelamentoMatricula/FimVida/Paginas/VFV.aspx $>$. Acesso em: 23/11/2020 
Pieroni, M. P., McAloone, T. C., Borgianni, Y., Maccioni, L., \& Pigosso, D. C. (2021). An expert system for circular economy business modelling: Advising manufacturing companies in decoupling value creation from resource consumption. Sustainable Production and Consumption, 27, 534-550.

POTTING, J.; HEKKERT, M.; WORRELL, E.; HANEMAAIJER, A. Circular Economy: Measuring innovation in the product chain - Policy report. PBL Netherlands Environmental Assessment Agency, , n. 2544, p. 42, 2017.

RIO GRANDE DO SUL. Lei 12.745 de 11 de julho de 2007. , 2007.

SINDIPEÇAS. Relatório da Frota Circulante 2018.

SOO, V. K. et al. Comparative Study of End-of-Life Vehicle Recycling in Australia and Belgium. Procedia CIRP,v. 61, p. 269-274, 2017. Disponível em: <http://dx.doi.org/10.1016/j.procir.2016.11.222

UNITED NATION. World Economic Situation and Prospects 2019

VALORCAR. Guia Desmantelamento de Veículos em Final de Vida. 2015.

VERMEULEN, I.; CANEGHEM, J. VAN; BLOCK, C.; BAEYENS, J.; VANDECASTEELE, C. Automotive shredder residue (ASR): Reviewing its production from end-of-life vehicles (ELVs) and its recycling, energy or chemicals' valorisation. Journal of Hazardous Materials, v. 190, n. 1-3, p. 8-27, 2011

XIA, X.; LI, J.; TIAN, H.; et al. The construction and cost-benefit analysis of end-of-life vehicle disassembly plant: a typical case in China. Clean Technologies and Environmental Policy, v. 18, n. 8, p. 2663-2675, 2016. Springer Berlin Heidelberg. 
